\title{
Discussion on the Artistic Language of Evaluation of Classroom Instruction
}

\author{
Haiyan Han ${ }^{1, \text { a }}$, Wen Zhi ${ }^{1, ~ b, *}$, Yueling Zhao ${ }^{2, ~ c}$, Lili Wang ${ }^{1, d}$ \\ ${ }^{1}$ College of Science, Changchun University, Changchun 130022, China; \\ ${ }^{2}$ School of Information technology, JiLin Agricultural University, Changchun 130118, China. \\ a453876175@qq.com, b314826346@qq.com, c275714495@qq.com, d378250645@qq.com
}

\begin{abstract}
Influenced by traditional teaching view, there are some old teaching thought and teaching habits now. The current classroom in practical evaluation, there are not adapt to the new teaching idea of teaching, Students' interest in classroom assessment is not too high, There is a high phenomenon such as low energy consumption course evaluation. Teacher in front of the update teaching material, the concept of innovation, unable to accurately grasp the essence of classroom assessment, purpose and tasks ,Can't find the real core course evaluation ,Can't system fully grasp the teaching material ,Cannot be easily and accurately control the classroom ,Cannot accurately more appropriate evaluation of students. So, based on the evaluation of language have the incentive and evaluation to give an accurate evaluation of language to appropriate, and discusses the three aspects, such as random strain. Therefore, this paper discusses the three aspects, Language must have the motivation and evaluates the language more accurate and decent, evaluation to improvise.
\end{abstract}

Keywords: The language of evaluation; Classroom teaching; Study quality.

\section{论课堂教学评价的艺术语言}

\section{韩海燕 ${ }^{1}$, 支文 $^{1, *}$, 赵月玲 ${ }^{2}$, 王丽丽 ${ }^{1}$ \\ 1. 长春大学理学院, 吉林长春 中国; \\ 2. 吉林农业大学信息工程学院, 吉林长春 中国}

摘 要: 受传统教学观的影响, 现在教学中还存在着一些旧的教学思想和教学习惯。当前的课 堂实际评价环节中, 还存在着不适应新的教学观的教学理念, 学生对课堂评价的兴趣还不太 高, 课堂评价存在着高耗低能等现象。教师面对教材的更新, 理念的革新, 无法准确地把握 课堂评价的本质、目的和任务, 找不到课堂评价的真正核心, 不能系统完整地把握教材, 不 能轻松、准确地驾驭课堂, 更不能准确得体地评价学生。所以, 本文从评价语言要有激励欣 赏性、评价语言要准确得体、评价语言要随机应变等三个方面进行探讨。

关键词: 评价语言; 课堂教学; 学习品质

\section{1. 前言}

所谓评价语言, 就是课堂教学中教师对学生的发言给予的评判, 指在教学过程中, 教师 对教学行为所作出的一种情感和行为的反应。学生时代正是知识积累和素质养成的关键时期, 有效的课堂评价可以引导学生对知识的探究和思索, 从而指导学生通过学习来获取知识和能 力, 令他们不致荒废高校的美好时光。因此, 深入开展教师评价语言研究对完善学生评价体 系是至关重要的。但受传统教学观的影响, 现在课堂教学中还存在着一些旧的思想和教学习 惯。当前的课堂实际评价环节中, 还存在着不适应新的教学观的教学理念。加之, 初、高中 的教学模式已使学生的思维模式化, 所以, 学生对课堂评价的兴趣还不太高, 课堂评价存在 着高耗低能等现象。教师面对教材的更新, 理念的革新, 无法准确地把握课堂评价的本质、 
目的和任务，找不到课堂评价的真正核心，不能系统完整地把握教材，不能轻松、准确地驾 驭课堂, 更不能准确得体地评价学生 ${ }^{[1]}$ 。所以, 本文就此论述评价语言要怎样才能符合如今 的教育形势。

\section{2. 评价语言要有激励赞赏性}

教师在备课时准备的课堂评价语言应突出学生在学习活动中的主体地位, 教师本人则应 给予指导和激励, 而不是将自己当做课堂的中心。不然不仅不能够发现学生自身的优点, 发 挥其主动性, 还会使学生对学习产生反感, 对课堂产生敷衍态度。每一个学生都有其自身的 优点及不足, 我们要尽力睁大眼睛发现学生的闪光点, 即使只有一句是精彩的, 哪怕只有一 个词是亮点, 我们也应该让学生知道他的耀眼光芒。这样, 学生的一点一滴的进步都在老师 眼中，学生感受到老师的关注后便更加愿意学习。

俗话说: “金无足赤, 人无完人。”学生在学习过程中的挫败是必然的, 当出现这现象 时老师应该更加关心学生, 首先要了解一下学生的心理及个性, 根据他们的情况来判断对他 们应该给予怎样的引导。也许有的学生会在开始的几次评价中回答得不尽人意, 这时, 是他 最需要教师引导和激励的时候, 不可对学生有 “朽木不可雕也, 弃之” 的想法。如果此时你 用一点激励的语言给予引导, 也许会让学生的成绩如鲲鹏展翅一飞冲天。

\section{3. 语言评价要准确得体}

教育, 说到底是培养人的活动。在学生心目中, 教师是知识和真理的化身。虽然, 现代 信息技术的发展, 使学生可以从多种渠道获取知识, 教师已经不是学生唯一的 “知识源”, 但学生对教师作为 “知识和真理的化身” 的要求与期待仍然没有减弱。教师不仅讲授言语要 言之有据, 课堂评价言语行为也要持之有据 ${ }^{[2]}$ 。每个人都有不同的认知特性, 不同的兴趣爱 好, 不同的欲望要求, 不同的价值取向, 不同的创造潜能......教师在课堂教学中, 用力较多 的是设计问题, 让学生回答问题, 对问题的解决过程较为重视, 而对学生的积极课堂评价关 注较少, 没有真正将培养学生的自主思考能力和探究能力作为课堂的重点, 同时课堂评价的 语言缺少准确性。教学艺术的本质不在于传授的本领, 而在于激励、唤醒和鼓舞。我们在课 堂上对学生进行评价时就要充分认识到这一点, 尽可能多地运用表扬武器, 做到 “好话多说, 坏话好说”, 帮助学生维持良好的情绪体验, 树立再创佳绩的信念。教育家陶行知先生说:

“教育是心心相印的活动, 惟独从心里发出来的, 才能打动心的深处。” 同样一个 “好”, 可以说得平淡如水, 让人有勉强之嫌, 也可以说得激情满怀, 让人感受到是你发自内心的赞 赏。

准确性是教师课堂评价语言的灵魂。如果说评价语言是一门艺术, 那么, 评价语言的真 诚贴切, 准确、得体则是其根本。教师的课堂评价语言一定要防止模棱两可、含糊不清等不 良倾向。评价语言要准确得体、因人而异, 要有点拨的作用, 对学生的学习要有针对性地给 予提醒或纠正, 以使学生知道自己思考问题时欠缺在哪里, 启发其思维。良莠不齐的学生素 质给课堂教学带来不小的冲击, 也给教师评价语言的组织带来一定的困难。因此在课堂教学 中, 教师应给予学生广阔的思维空间, 让他们尽情地表达自己的看法。在此基础上, 教师通 过评价提升学生认识的高度, 增加课堂交流的厚度, 挖掘课堂的深度和价值。

对于学习品质优异的学生而言, 他们已经形成良好的学习习惯, 学习课本上的知识对于 他们是轻而易举的事情, 因此我们在课堂上对他们的评价, 不能停留在简单地肯定理论知识 的层次上, 而应该是选择独特的角度, 开阔学生视野, 激发深入思考、探究的欲望, 使他们 的学习进入更深层次; 学习品质一般的学生在班内占多数, 他们有向学习品质优异学生靠近 的愿望, 但学习积极性不持久, 还没有找到激发学习潜力的激发点。我们在评价时就要侧重 对他们学习态度的鼓励与欣赏、对知识正误及学习方法的点评; 对于学习品质稍差的学生而 言, 他们通常理解能力、记忆能力及主动学习意识等方面都存在问题, 教师在对他们进行评 
价时 “左” 倾了, 会伤害学生的自尊心, “右” 倾了, 无法起到整体优势的作用, 他们的共 同点是缺少自信心, 最需要的是鼓励。我们在评价他们时更要小心谨慎, 不能敷衍了事, 要 从他们身上去发现他们亮点, 还要引导他们认识到自己的亮点, 从而发现自己的价值所在。 课堂评价应该是在尊重学生人格基础上的科学评价。教师应多给学生一些空间. 这样学生才 能求得生存, 求得发展 ${ }^{[3]}$ 。

\section{4. 评价语言要随机应变}

一本教材中蕴含着十分丰富的信息量, 在教学过程中又充满着各种变化、发展, 始料不 及的情况, 这就要求教师在进行课堂评价时, 灵活运用教学机智, 将预设性语言和随机性语 言结合起来, 根据学生的反馈信息、突发情况, 临时调整原先预设的口语流程, 快速反应, 巧妙应对, 随机评价, 能收到意想不到的效果。优秀的教师都会把语言当作心灵的粘合剂, 以生动优美或诙谐幽默的语言作媒介, 弥补师生之间可能产生的代沟, 促进师生之间的心灵 沟通 ${ }^{[4]}$ 。教师课堂教学评价语言应因境、因事、因人而随机应变, 用自己内在的语言魅力, 创造性地对学生进行评价, 激励学生积极地参与到课堂教学活动中, 使教学达到令人难以忘 怀的境界。

教师课前准备得再充分也会在课堂上遇到尴処的时候, 学生认知的不同就会出现不同的 状况; 学生的集中力不同就会出现涣散到其他事情的问题; 学生的感受不同就会出现感情释 放的问题……这些种种, 都考验着教师的语言驾驭能力和随机应变能力。

教师没有一个不是真心希望学生能够成长的, 而且是在自己的鼓励下一点一滴的茁壮成 长。所以, 学生的成长也与老师心贴心的教诲息息相关, 只有心心相印才能让学生更好地成 长。

\section{5. 结论}

课堂评价的核心功能在于促进学生的学习。这是由课堂评价的性质决定的。课堂评价不 是凌驾于教学之上的一个孤立的环节, 而是镶嵌于教学过程之中, 与教学活动紧密的缠绕在 一起的, 是教学的一个有机组成部分 ${ }^{[5]}$ 。课堂评价同时也是学生获取知识、提升能力的重要 途径, 是学生获取外界信息, 提高自身综合素质的重要媒介。在教学中开展问题评价和解惑, 可以激发学生的课堂学习兴趣, 有助于增强学生学习的内驱力, 可以实现师生的有效互动, 在问题的交流中获得教与学的共同进步。但当前的课堂实际评价环节中, 还存在着不适应新 的教学观的教学理念, 学生对课堂评价的兴趣还不太高, 课堂问题教学中还存在着高耗低能 的现象。为此, 在今后的教学中, 我们应该通过多种形式提高教师的课堂评价水平。教育的 艺术是一种谈话的艺术, 教师的教学效果很大程度上取决于教学语言。只要教师加强教学评 价艺术的修养, 正确运用评价语言和方式, 用心去品评学生的语言, 一定可以点燃学生智慧 的火花, 激发学生学习的热情, 使课堂充满生机, 从而提高课堂教学效率与活力。

\section{致谢}

作者简介: 韩海燕 (1974.10), 女 (汉族), 长春大学理学院助理研究员, 主要研究方 向为教学管理。本文受课题项目 “基于ZigBee通信技术下的配电登杆作业实训安全智能电子 监护系统的设计与应用” 资助。（项目编号：2015LY708L01）

\section{References}

[1] Haihong Sun, Evaluate the effectiveness of the language study class. China's school education (under ten-day), 2014(10). 
[2] Changping Lu, teacher's classroom assessment speech ACTS pragmatic principles. Journal of anhui normal university.2010 (1).

[3] Jinzhi Hu, The problems existing in the language classroom evaluation and optimization strategy. The exam week.2013 (52).

[4] Wei Lu, Teachers classroom evaluation quality standards research. Education science .2007(10).

[5] Shaofei Wang, Weiqiang Zhu, Classroom assessment of cognitive function and its implementation. The contemporary teaching science.2014 (20). 